\title{
Physical And Mechanical Properties Of Injection Molding For Waste Polypropylene Rice Husk Composite (Wpc) Upon Water Absorption And Uv Irradiation Expossure
}

\author{
Ahmad Shahrizan Syah, Anika Zafiah M. Rus, Aida Nur Aisyah A., Farhana Hazwanee M. Jais, N.Afiqah Sufian, M. \\ Zulhafiz Z., M.Zulkhairi Jailani, Najah Anis A. M. I., N. A. Irna M. Radzi, ${ }^{2}$ Norlaili Amir.
}

Sustainable Polymer Engineering, Advanced Manufacturing and Material Center (SPEN-AMMC),

Faculty of Mechanical and Manufacturing Engineering,

Universiti Tun Hussein Onn Malaysia, 86400 Parit Raja, Batu Pahat, Johor, Malaysia.

${ }^{2}$ Mechanical Engineering Department, Universiti Teknologi PETRONAS Bandar Seri Iskandar, 32610, Perak, Malaysia.

E-mail: zafiah@uthm.edu.my

Correspondence Author: Anika Zafiah M. Rus, Sustainable Polymer Engineering, Advanced Manufacturing and Material Center (SPEN-AMMC), E-mail: zafiah@uthm.edu.my

Received date: 22 December 2017, Accepted date: 22 January 2018, Online date: 5 February 2018

Copyright: (C) 2018 Anika Zafiah M. Rus. This is an open-access article distributed under the terms of the Creative Commons Attribution License, which permits unrestricted use, distribution, and reproduction in any medium, provided the original author and source are credited.

\begin{abstract}
The feasibility of Wood Polymer Composites (WPCs) on an industrial scale is essential that the performance of WPCs is well characterized, from their production process to the requisites for their various applications in the industrial building construction or furniture industries. WPCs are combination of polymer with different composition of additives such as wood fiber of rice husk (RH). The preparation of the solid WPCs is comprises on the predetermined temperatures for injection molding between $50^{\circ} \mathrm{C}$ to $220^{\circ} \mathrm{C}$ at different machine zones. The physical characterization approached on WPCs samples is water absorption test in Ultra-Violet irradiation exposures at $32^{\circ} \mathrm{C}$. The WPCs is then were analysed on its morphological changes of the fiber particle size of $\mathrm{RH}$ after both treatment. The result shows the highest percentage of water absorption is $2.82 \%$ in which increased of RH content lead to increasing the water absorption rate. It directly affects the thickness of WPCs with swelling value of $1.94 \%$. As compared the composition ratio, the highest RH content in WPCs lead to higher density values. Hardness value was decreasing respectively for all WPCs due to increase of immersion hours but with respect to the highest hardness of $14.5 \mathrm{kN}$ is from the highest RH content. The study is important in the application of RH filled polymer composites as an alternative material in industrial building construction due to its light weight, renewable and low cost.
\end{abstract}

Key words: Wood polymer composites, injection molding, physical properties, rice husk, waste polypropylene

\section{INTRODUCTION}

A wood polymer composite is an environmental improvement way of combining waste plastics and wood flour. The composite typically consists of four major elements which are wood flour, thermoplastic plastics, coupling agent, and lubricant [1]. Coupling agents are often added in WPC to increase the bonding between wood flour and the matrix while lubricants are used to improve the process capability for extrusion. Due to a shortage of resources and a growing competition for land use, sustainable and efficient resource utilization becomes progressively important. WPC are a group of innovative materials involving of mainly renewable resources [2].

Some of the advantages of WPC that make it used widely are WPC usually, low price and profiles are easily made of from waste plastics and wood fibers [3]. Consequently, low manufacturing and processing cost is expected due to the materials used and the production cost can be done minimally. WPC is durable which means it is not corroded or decay due weather, especially on the outside use. Another advantage of WPC is easily mold-able, it has great workability and can be shaped using traditional woodworking tools. Advantages of using WPC can be clearly seen by comparing the WPC boards properties with the timber boards. By the time, the used of WPC in many applications such as construction and furniture materials make the demand for this material is high.

\section{Methodology:}

For this study, samples preparation is starting by taking pellets from the industry. Injection molding is used to extrude the pellets into dumbbell shape which is used as test samples. Different type of WPC samples based on the different composition ratio of recycling polypropylene and rice husk known as F1, F2, F3, F4, F5, F6, and F7 will be used to conduct the physical and morphological properties test.

Materials:

Different composition ratio was used in the preparation of pellets. Table 1 shows the composition ratio of the waste polypropylene and rice husk. 
Citation: Ahmad Shahrizan Syah, Anika Zafiah M. Rus, Aida Nur Aisyah A., Farhana Hazwanee M. Jais, N.Afiqah Sufian, M. Zulhafiz Z., M.Zulkhairi Jailani,Najah Anis A. M. I., N. A. Irna M. Radzi, Norlaili Amir, 2018. Physical And Mechanical Properties Of Injection Molding For Waste Polypropylene Rice Husk Composite (Wpc) Upon Water Absorption And Uv Irradiation Expossure. Advances in Natural and Applied Sciences., 12(1): 32-36.

\begin{tabular}{|l|l|l|}
\hline \multirow{2}{*}{ Formula } & Materials & Rice Husk (\%) \\
\cline { 2 - 3 } & Waste Polypropylene (\%) & 70 \\
\hline F1 & 30 & 60 \\
\hline F2 & 40 & 50 \\
\hline F3 & 50 & 40 \\
\hline F4 & 60 & 30 \\
\hline F5 & 70 & \\
\hline F6 & 80 & 20 \\
\hline F7 & 100 & \\
\hline
\end{tabular}

\section{Preparation of WPC Samples:}

Preparation of WPC test samples consists of two processes which are extrusion of pellets and injection molding of dumbbell samples. The pelletizing process by using Continuous Compounder Equipment while Injection Molding machine used is Nissei NP7 Real Mini with the horizontal screw type to produce WPC samples as according to with ISO $527(5 \mathrm{~A})$ standard. The temperatures setting at nozzle, front, middle, rear 1 , rear 2 , feed was $220^{\circ} \mathrm{C}, 205^{\circ} \mathrm{C}, 215^{\circ} \mathrm{C}, 200^{\circ} \mathrm{C}$, $175^{\circ} \mathrm{C}, 50^{\circ} \mathrm{C}$ respectively. The pressure was set to $56.35 \mathrm{MPa}$ and the velocity was $35 \mathrm{~cm}^{3} / \mathrm{s}$.

\section{Water Absorption Test:}

The water absorption test was conducted according to ASTM D570. The UV weatherometer is used to simulate the real condition of Ultra-Violet irradiation exposures. Water absorption test with UV irradiation exposures at 100 to 500 hours with the increments of 100 hours were conducted.

The setting temperature is $32^{\circ} \mathrm{C}$ is based on the temperature from sunlight. The percentage of water absorption calculates by using the equation:

$\mathrm{WA}=\frac{w f-w i}{w_{j}} \times 100 \%$

Where WA is the amount of water absorbed, Wi is the initial weight of the sample and Wf is the final weight of the sample.

Thickness Swelling Test:

The thickness swelling test was conducted according to ASTM D570 while the dimension stability test is conducted to measure the dimension of WPC samples is following the standard of ISO 527-5A. The thickness of the sample is measured before and after conducting the water absorption test by using digital Vernier caliper. The percentage of thickness swelling was calculated by using the equation:

$\mathrm{TS}=\frac{\tau f-\tau i}{\tau i} \times 100 \%$

Where TS is the percentage of thickness swelling, Ti is the initial thickness of the sample and $\tau f$ is the final thickness of the sample.

Density Test:

The density of WPC samples was measured by using AD-1654 density balance machine. It is conducted according to ASTM D792. The density was calculated by using equation below:

$$
\rho=\frac{A}{|E|} \times \rho_{0}
$$

Where $\rho$ is the density of sample, A is the weight of sample in air, $|\mathrm{B}|$ difference of sample in air and distilled water and $\rho$ is density of distilled water $(\mathrm{g} / \mathrm{cm} 3)$.

\section{Hardness Test:}

Hardness test was done to measure the WPC samples by using Shore Durometer Type D. It is done manually by applying the pressure using one hand only.

Tensile Test:

Morphological Property Test:

Optical Microscope is used to capture WPCs morphological images. The images are used to identify either the WPC composites undergoes expansion or contraction based on the RH particles size.

Results:

Physical properties test for WPC samples known as F1, F2, F3, F4, F5, F6, F7 is compared. The data collected from the water absorption test in UV irradiation exposure at $32^{\circ} \mathrm{C}$ using weatherometer at different immersion times. The test is done from 100 hours to 500 hours with an increment of 100 hours. The changes in physical properties is observed and examined on the sample before and after the treatment. Particles size of rice husk measured from morphological test was compared between WPC samples.

Effect of parameters on injection moulding process of WPC samples:

The lowest temperature is determined based on the polypropylene melting point temperature which is $170^{\circ} \mathrm{C}$ to $185^{\circ} \mathrm{C}$ (Behravesh et al, 2009). The upper limit of temperature is based on the wood degradation temperature at $220^{\circ} \mathrm{C}$ [4]. Based on the limit of the temperature, it will be leading to the high rate in the injection process and cause a high heat generation. It will increase the possibility of wood degradation. 


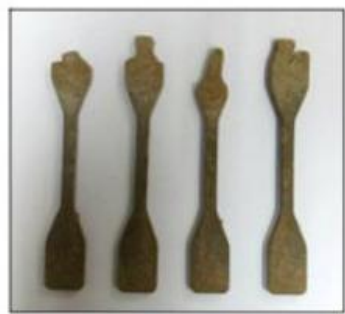

(a)

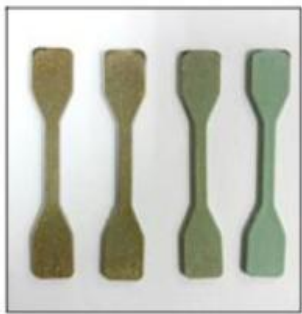

(b)

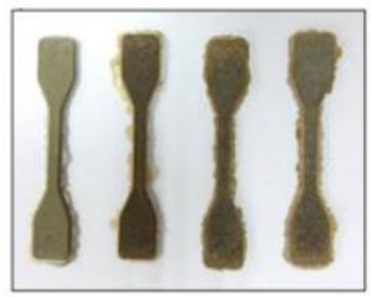

(c)

Figure 1: Defect WPC sample (a) Uncompleted shape (b) Burned part (c) Swelled part produced by inappropriate injection moulding setting parameters

Physical properties test result:

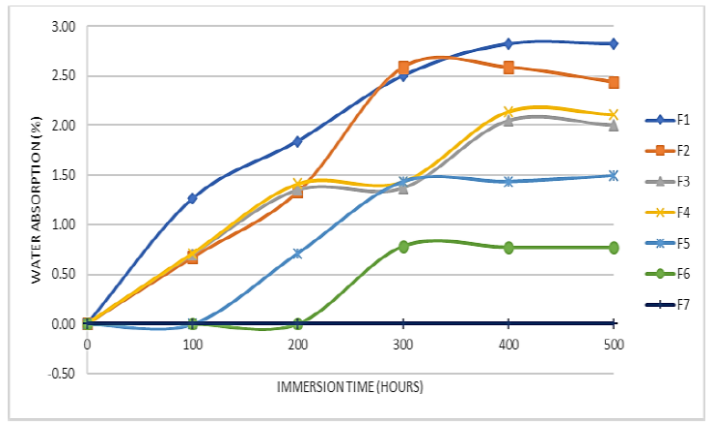

Fig. 2: Percentage of water absorption test with UV irradiation exposure in UV weatherometer at $32^{\circ} \mathrm{C}$ of F1, F2, F3, F4, F5, F6 and F7

The percentage of water absorption increases as the immersion time increased. The saturation point of WPCs samples is observed when the water immersion time at 300 hours to 400 hours. WPC samples show the decreasing in water absorption at 500 hours. It can be summarized that the higher the content of wood fiber (rice husk) in WPC samples lead more absorption of water. Instead of the water absorption of WPC samples decreased with increasing of polypropylene filler. Meanwhile, the wood fiber consists of carbohydrate and lignin which are hydroscopic substances lead to higher water absorption property. El-Meniawi [7] stated as the polypropylene is hydrophobic and wood fiber is hydrophilic, thus, the absorption water of WPC samples is relying on the wood fiber substances only.

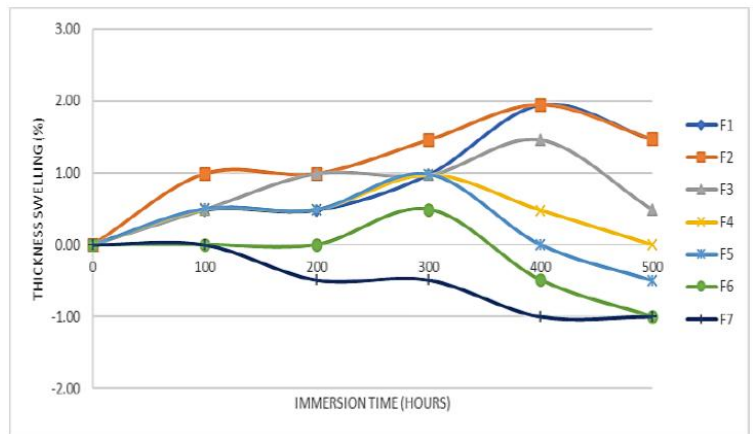

Fig. 3: Percentage of thickness swelling test with UV irradiation exposure in weatherometer at $32^{\circ} \mathrm{C}$ of $\mathrm{F} 1, \mathrm{~F} 2, \mathrm{~F} 3, \mathrm{~F} 4, \mathrm{~F} 5, \mathrm{~F} 6$ and $\mathrm{F} 7$

Thickness swelling occurs when moisture was build up in the fiber cell wall and in the fiber matrix interface. The highest percentage thickness swelling was from F1 and F2 at 400 hours with $1.94 \%$ and $1.93 \%$ respectively. For all WPC samples except for F7, the percentage of thickness swelling was increased before it changed to decreasing trend. The decreasing percentage of thickness swelling occurred at immersion time at 300 hours and 400 hours based on the composition of WPC samples. The thickness swelling of WPC changes due to the composition of rice husk and waste polypropylene. It also changes when the immersion time of water absorption was increased. The effect from the swelling can be seen from its properties. According to Ashori et al. [5], stress on fiber imminent when swelling happen lead to the microcracking and causes the composite to fail catastrophically. As significance, the fiber matrix adhesion is weak and the dimensional stability of composites mostly for outdoor applications will be seriously affected. 
Citation: Ahmad Shahrizan Syah, Anika Zafiah M. Rus, Aida Nur Aisyah A., Farhana Hazwanee M. Jais, N.Afiqah Sufian, M. Zulhafiz Z., M.Zulkhairi Jailani,Najah Anis A. M. I., N. A. Irna M. Radzi, Norlaili Amir, 2018. Physical And Mechanical Properties Of Injection Molding For Waste Polypropylene Rice Husk Composite (Wpc) Upon Water Absorption And Uv Irradiation Expossure. Advances in Natural and Applied Sciences., 12(1): 32-36.

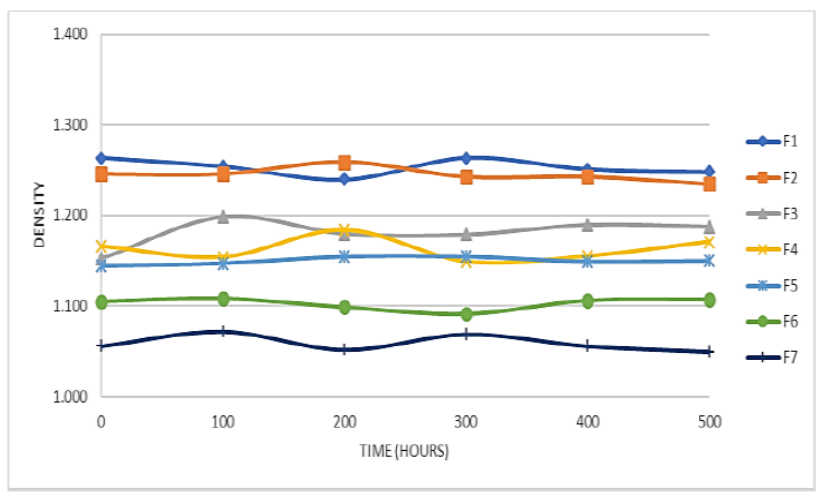

Fig. 4: Density of water absorption test with UV irradiation exposure in weatherometer at $32^{\circ} \mathrm{C}$ of $\mathrm{F} 1, \mathrm{~F} 2, \mathrm{~F} 3, \mathrm{~F} 4, \mathrm{~F} 5, \mathrm{~F} 6$ and $\mathrm{F} 7$

Based on the density values, the range of the value is from $1.263 \mathrm{~g} / \mathrm{cm}^{3}$ to $1.050 \mathrm{~g} / \mathrm{cm}^{3}$. It shows the value of composites is higher than the density value of polymer matrix. The highest value of density comes from WPC sample of F1. Meanwhile the lowest value of density is from F7. For sample F3, F4, and F5, the density value is almost the same as the content of the rice husk composition ratio slightly different. It seems there is a slight tendency of increasing density with increasing of rice husk content. By comparing the density due to water absorption test, the test does not affect the density value of WPC sample. There is slightly different between the highest and lowest value of F1 which is $0.023 \mathrm{~g} / \mathrm{cm}^{3}$. It can be concluded the WPC is a very light material which can be used for applications that required low weight [6].

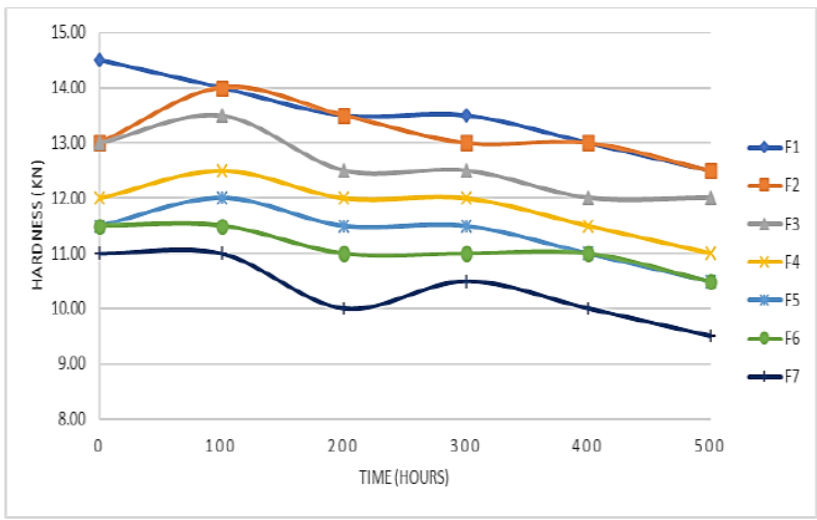

Fig. 5: Hardness Shore-D of water absorption test with UV irradiation exposure in UV weatherometer at $32^{\circ} \mathrm{C}$ of F1, F2, F3, F4, F5, F6 and F7

As reffered to Figure 5, the shore-D hardness values of WPCs shows significant increased with increasing of RH content. Instead, uses of the waste polypropylene in WPCs results in decreasing of shore-D hardness value. Decreasing of hardness value is due to poor adhesion at the surfaces between fiber filler particles and polymeric matrix [7].

As the water absorption hours of WPC sample increased, the shore D hardness gradually decreased. Initially, the shore-D hardness value for F1 is $14.50 \mathrm{kN}$ at 0 hours. As the WPC sample undergo water absorption test for 100 hours, 200 hours, 300 hours, 400 hours and 500 hours, the shore-D hardness value was slightly decreased. UV irradiation exposure causes the degradation of both materials which are wood and plastic materials [8]. Since WPC is porous material with hydroscopic properties in which water in a material act as a catalyst to oxidation that causes degradation of WPC samples.

Mechanical properties test result:

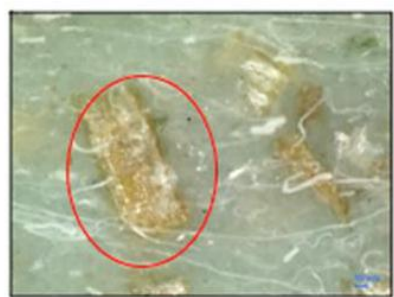

(a)

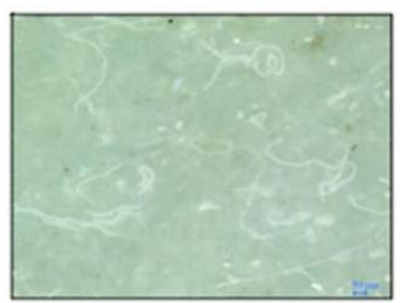

(b)

Fig. 6: Materials references of WPC samples (a) Particle of rice husk at $50 \mu \mathrm{m}$ and (b) Waste polypropylene.

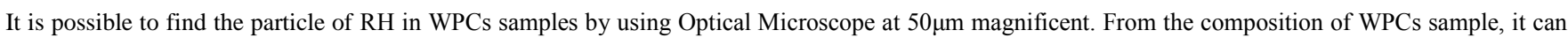
be seen that the content of RH decreased from F1, F2, F3, F4, F5, F6, and F7. For F7, none of RH particle was observed as the composition is $100 \%$ of recycling polypropylene.

RH particle of WPCs samples from F4, F5, and F6 is easy to be observed as compared to F1, F2, and F3. Clear image of RH particle were identified as in Figure 4 with higher duration of water absorption test in UV irradiation exposure. It shows the RH particle is pulling off from the composite as the time of water absorption test increased. Following the result of water absorption test, the particle size of RH is increased from 0 to 400 hours and decreased at 500 hours. Increased in RH particle sizes is due to the absorption of water that leads to the expansion of the WPCs samples.

The observation of the decreasing in RH particle size was an effect from UV irradiation exposure in weatherometer at ambient temperature with the increasing of exposure time. The action of UV irradiation exposure on polymer and moisture on the wood will lead to small expansion and contraction [9]. 


\section{Conclusion:}

The fabrication of WPCs samples at predetermined temperature setting of injection moulding used are $220^{\circ} \mathrm{C}, 205^{\circ} \mathrm{C}, 215^{\circ} \mathrm{C}, 200^{\circ} \mathrm{C}, 175^{\circ} \mathrm{C}$ and $50^{\circ} \mathrm{C}$ for the nozzle, front, middle, rear 1 , rear 2 and feed respectively with pressure at $56.35 \mathrm{MPa}$ and velocity of $35 \mathrm{~cm}^{3 / \mathrm{s}}$. Following the injection moulding parameter setting, the WPCs samples produced have good shape and dimensions regardless of some defect with incomplete shape, burned part and swelled part occurred when impropriate parameter applies during the process. WPCs that undergo water absorption test in UV irradiation exposure in weatherometer revealed slightly increased the percentage of water absorption due to increase duration of water immersion and the RH content. The changes in thickness swelling lead to stress on $\mathrm{RH}$ fiber that cause the composite to fail. Initially, the hardness value of F1 was the highest compared to others with 14.50 but decreases as the water absorption time increased. By reducing the RH content and increased water immersion time in UV irradiation exposure, the fibers and waste thermoplastic polymer was softened and the composites showed plastic matrix deformation via the hardness test. The study on interfacial adhesion of fiber filled polymeric materials are needed due to the reason is that fiber-polymer interaction is important in determining the final composite properties as well as processing condition. With excellent values of physical properties, WPCs is suitable for construction such as decking, floor, or wall for industrial building construction.

\section{ACKNOWLEGEMNETS}

The author would like to thanks Sustainable Polymer Engineering, Advanced Manufacturing and Materials Centre (SPEN-AMMC), University Tun Hussein Onn Malaysia (UTHM), Johor and Malaysian Government for supporting this research under IGSP vot U678 and Universiti Teknologi Petronas (University Research Internal Fund) collaboration with SPEN-AMMC, UTHM vot A136 and ZFH Sdn Bhd for machine used and collaboration.

\section{REFERENCES}

[1] Yang, T.H., S.Y. Leu, T.H. Yang, and S.F. Lo, 2012. "Optimized material composition to improve the physical and mechanical properties of extruded woodplastic composites (WPCs)," Constr. Build. Mater., 29: 120-127.

[2] Teuber, L., V.S. Osburg, W. Toporowski, H. Militz and A. Krause, 2016. "Wood polymer composites and their contribution to cascading utilisation," J. Clean. Prod., 110: 9-15.

[3] Carus, M., C. Gahle and H. Korte, 2008. "Market and future trends for wood-polymer composites in Europe: the example of Germany.," Wood-Polym. Compos. pp: 300-330.

[4] Behravesh, A.H., A. Zohdi Aghdam and E. Soury, 2009. "Experimental Investigation of Injection Molding of Wood/Plastics Composites," J. Reinf. Plast. Compos., 29(3): 456-465.

[5] Ashori, A. and S. Sheshmani, 2010. "Hybrid composites made from waste materials: Moisture absorption and thickness swelling behavior," Bioresour. Technol., 101(12): 4717-4720.

[6] Maria, S., L. Rosa, E. Fonseca, P.O. Box and P.A. Rs, 2009. "Studies on the Properties of Rice-Husk-Filled-PP Composites - Effect of Maleated PP 2 . Experimental Procedures," Mater. Res., 12(3): 333-338.

[7] EL-Meniawi, M.A.H., 2017. "Characteristics of Polypropylene / Wood-Flour Composites ( WPCs )," no. 1: $1469-1474$.

[8] Hyv, M., 2014. Ultraviolet Light Protection and Weathering Properties of Wood-Polypropylene Composites.

[9] Spear, M.J., A. Eder and M. Carus, 2015. Wood polymer composites. Elsevier Ltd. 